degraded tropical habitats.

Rhett D. Harrison

Xishunagbanna Tropical

Botanical Garden, Chinese

Academy of Science, Menglun,

Yunnan, China.

rharrison@xtbg.org.cn

\section{Tropical forests: try holistic conservation}

Sustaining tropical biodiversity in the long term requires more than just protection of remaining primary forests (L. Gibson et al. Nature 478, 378-381; 2011). It is essential to encourage landuse strategies that increase the potential conservation value of habitats modified by humans. Substantial tropical biodiversity can also thrive in such humandominated ecosystems.

Luke Gibson and colleagues highlight the importance of disappearing forests by comparing biodiversity in tropical primary forests with corresponding human-modified habitats. But clinging to the ecological ideal excludes equally important comparisons to ecological dystopias. For example, when I re-analysed the data to include a 'degraded' reference state with poor biodiversity (see www. stanford.edu/ cdm/Pubs/SOM), it revealed that human-dominated ecosystems sustain at least a medium amount of biodiversity. This is substantial, considering that such ecosystems constitute roughly $85 \%$ of the tropics (E. C. Ellis et al. Global Ecol. Biogeogr. 19, 589-606; 2010).

Rather than championing conservation of primary forest over land-use strategies favouring conservation, we must develop a holistic conservation model that includes humandominated ecosystems. Chase D. Mendenhall Center for Conservation Biology, Stanford University, California, USA. cdm@stanford.edu

\section{Tropical forests: include Congo basin}

Luke Gibson and co-workers provide an important global assessment of the impact of disturbance and land conversion

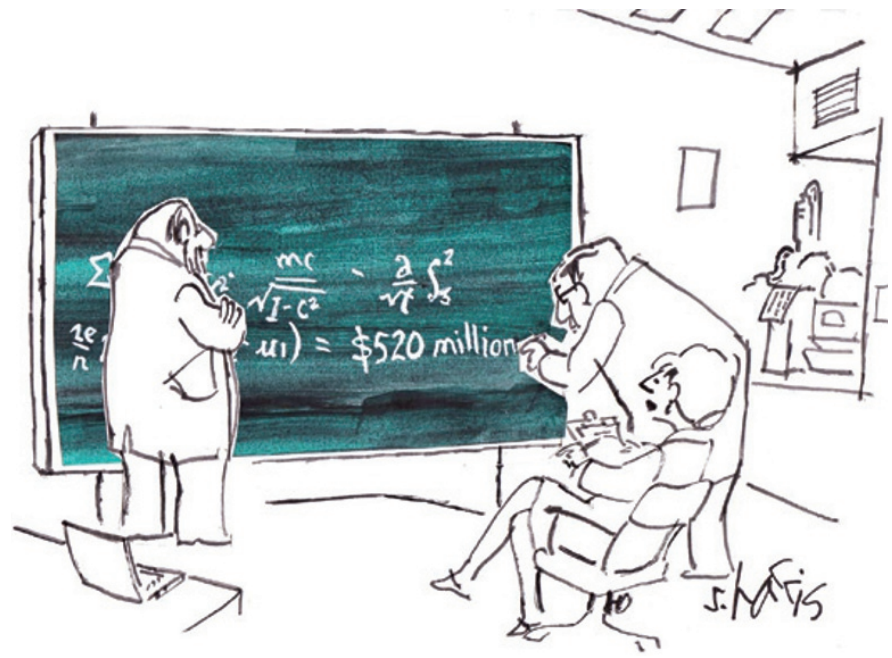

on biodiversity in tropical forests (Nature 478, 378-381; 2011). But their meta-analysis of 138 studies overlooks the Congo basin, the second-largest continuous area of rainforest in the world; moreover, only 12 studies are located in Africa. This omission is not the fault of the authors, but is symptomatic of the lack of recent and accessible legacy data for this region.

The Democratic Republic of Congo (DRC), which contains 98 million hectares of rainforest (60\% of the Congo basin forest), is also poorly represented in studies beyond biodiversity. Take, for example, a study that estimates the carbon sink in the world's forests on the basis of inventory data and long-term ecosystem studies (Y. Pan et al. Science 333, 988-993; 2011). The study's estimate for carbon stocks in intact tropical forest across Africa is based on a network of 79 monitoring sites, yet only ten of these are in the DRC, all in the same forest reserve in the northeastern Ituri province.

Large scientific, logistic and training efforts are needed to establish permanent monitoring sites in the Congo basin's tropical forests and woodlands, and to connect those sites to global networks.

Countries such as the DRC must also identify and monitor forest biodiversity and carbon stocks within the framework of international climate and conservation policies, such as the United Nations REDD programme (for 'reducing emissions from deforestation and forest degradation'). This will help to preserve the Congo basin forest, where deforestation so far remains modest compared with that in the Amazon region and in southeast Asia.

Hans Verbeeck, Pascal Boeckx, Kathy Steppe Ghent University, Belgium.

hans.verbeeck@ugent.be

\section{Clarifying the use of 'prepubescent'}

By implying that 11- and 12-year-old girls are "prepubescent", you play into the hands of those who oppose vaccinating young girls against human papilloma virus (HPV) to prevent cervical cancer (Nature 477, 369; 2011).

Although the average age of first menstruation (menarche) was 12.8 years in the United States in 1968 , this is becoming steadily younger (see, for example,

S. E. Anderson and A. Must J. Pediatr. 147, 753-760; 2005). Also, as menarche comes quite late in a girl's progress towards full adult height and reproductive capacity, girls should no longer be described as prepubescent at ages 11 and 12 .

A case could be made for scheduling vaccination against $\mathrm{HPV}$ at an even younger age - at the start of breast development, or around age 10 , before a girl is likely to become sexually active.

Evelyn J. Bowers Ball State

University, Muncie, Indiana,

USA.

o0ejbowers@bsu.edu

\section{More than one fund for US entrepreneurs}

There are more funding opportunities for entrepreneurial US scientists than Steve Blank conveys (Nature 477, 133; 2011). These are especially pertinent in a year when the National Science Foundation (NSF) is seeking congressional reauthorization for its Small Business

Innovation Research (SBIR) Program.

Although the NSF's US\$5-million Innovation Corps (I-Corps) initiative is welcome, the SBIR Program has available funds of about $\$ 150$ million a year. Overall, SBIR programmes at the NSF, NASA and the US government departments of energy, defence and commerce provide $\$ 2$ billion in funding a year. Since their inception in 1982, they have enabled a whole generation of scientists to become entrepreneurs.

The I-Corps sends funding directly to universities rather than to small businesses. However, many SBIR-funded small businesses were originally university spinoffs, and the complementary Small Business Technology Transfer (STTR) programme already targets partnerships between universities and small businesses.

Probably the most innovative element of the I-Corps programme is its partial funding by private foundations. If this could be increased, it would help to alleviate pressure on federal funding of the SBIR and STTR programmes.

SBIR funding was significant to the success of both of the science-entrepreneurial spin-offs in which I was involved after leaving Harvard University (see www.aer.com and www.cri-inc.com). These companies have since gone public, having generated products for worldwide use in applications ranging from biomedical imaging to environmental control.

Peter Foukal Nahant, Massachusetts, USA. pvfoukal@comcast.net 